\title{
Ensino na Saúde em Tempos de Covid-19: Acesso, Iniquidades e Vulnerabilidade
}

\author{
Health Education in Times of Covid-19: Access, Inequities and Vulnerability
}

Francis Solange Vieira Tourinho' $\mathbb{D}$, Gustavo Antonio Raimondi" $\mathbb{D}$

Este suplemento da Revista Brasileira de Educação Médica (RBEM), intitulado "Ensino na saúde em tempos de Covid-19: acesso, iniquidades e vulnerabilidade", apresenta para a Educação Médica caminhos possíveis para reflexões sobre algumas realidades de populações vulnerabilizadas em nosso país e a relação com o ensino e o cuidado em saúde durante a pandemia provocadas pela síndrome respiratória aguda grave do coronavírus 2 (severe acute respiratory syndrome coronavirus 2 - SarsCoV-2), causadora da coronavirus disease 2019 (Covid-19). É também um suplemento que desperta um modo de olhar a saúde e o ensino pautado nos Direitos Humanos e na (re)existência das vidas que por muito tempo sofreram, e ainda sofrem, a indiferença na formação das universidades.

Vulnerabilidade é uma perspectiva multifacetada, com significados diferentes e inúmeras implicações. Uma constante para estudiosas(os) da área é a compreensão da vulnerabilidade a partir dos Determinantes Sociais em Saúde, bem como dos fatores políticos, culturais, econômicos e técnicos que contornam a incidência e a manutenção de determinados riscos em saúde1. Associada a isso, a perspectiva de iniquidades em saúde aponta para as situações que colocam determinados sujeitos e coletivos em desvantagem de acesso e cuidado em relação à saúde. Trata-se de situações que poderiam ser reduzidas, mas são sistematicamente perpetuadas². Diante disso, como temos pensado o acesso à saúde e suas interfaces na formação em saúde, especificamente na educação médica, em tempos de pandemia da Covid-19?

Sabemos que, durante a pandemia e ao longo de 2020, houve um incremento das vulnerabilidades e iniquidades, com implicações em um acesso oportuno e de qualidade à saúde 3,4 . Essa situação associada, por exemplo, com o empobrecimento, o aumento da violência e o desemprego crescentes da população aponta para um cenário de saúde preocupante. E, em certa medida, essa conjuntura será irreversível se a sociedade, principalmente educandas(os) e educadoras(es) da área médica, não pensarem e implementarem estratégias seguras e aplicáveis a algumas realidades dessa população, problematizadas neste suplemento. Por isso, é fundamental compreender que as afirmativas "A Covid-19 não discrimina quem adoecerá"3 e "Estamos todos no mesmo barco"s são mitos que mascaram a marginalização vivenciada por determinados grupos em relação ao cuidado e ao ensino na área da saúde ${ }^{3-9}$.

É imprescindível que educandas(os) e educadoras(es), bem como as universidades e o Estado, estejam atentas(os) às realidades problematizadas neste suplemento, bem como a tantas outras que foram explicitadas durante a pandemia da Covid-19, para que possam refletir sobre os seus compromissos constitucionais ${ }^{10}$ de democracia e de direito à saúde. Com isso, é necessário, por exemplo, compreender e pensar caminhos possíveis para articular a democratização do acesso a um nível superior de ensino que exige processo seletivo e, ao mesmo tempo, garantir a qualidade do ensino superior a todas(os) as(os) estudantes, adequando-se às situações geradas pela pandemia, que revelam as diferenças de acesso à tecnologia costumeiramente marcadas por desigualdades econômicas.

Neste suplemento, as(os) autoras(es) apresentaram artigos com as linhas temáticas propostas pela RBEM: inclusão/ exclusão digital; desafios/potencialidades das Políticas Afirmativas; iniquidades e seu impacto no trancamento/abandono do curso; estratégias para permanência da(o) estudante; avanços curriculares em Direitos Humanos; populações invisibilizadas e diversidades; e desenvolvimento docente para o mundo pós-pandemia.

'Mulher-cis, negra, mãe de gêmeos, professora da Universidade Federal de Santa Catarina, Florianópolis, Santa Catarina, Brasil. "Homem-cis, gay, branco, professor da Universidade Federal de Uberlândia, Uberlândia, Minas Gerais, Brasil.

Correspondência:

Francis Solange Vieira Tourinho.

Caixa Postal 5039, AC Cidade Universitária (UFSC), Rua Roberto Sampaio Gonzaga, s/n, Trindade, Florianópolis, SC, Brasil. CEP: $88040-970$.

E-mail: francis.tourinho@ufsc.br 
A pandemia eas situações emergentes-em consequência dos fatores psicossociais, biológicos e educacionais - mostraram que são fatores potencializadores de vulnerabilização da sociedade, como veremos em três artigos que nos remetem a refletir sobre questões de vulnerabilidade, empobrecimento e desemprego durante a pandemia. Há ainda as incertezas na formação médica e em saúde em decorrência dessas transformações, e as dúvidas sobre esses fatores e influência deles no período pós-Covid-19, o que corrobora a publicação deste suplemento especial. É imprescindível destacar que o ensino e cuidado em saúde devem se pautar na diversidade e diminuição das iniquidades em saúde, de modo a contribuir para o melhor preparo dos profissionais.

Nesse ínterim, outros manuscritos refletem sobre a evidência de aprimorar a formação e consequentemente a atuação médica que reiterem o direito à saúde e as reais necessidades dos grupos invisibilizados. Esse debate está relacionado às situações vivenciadas pela população negra em interface com o racismo estrutural brasileiro; às pessoas em situações de rua com seu desamparo institucionalizado; às populações indígenas, histórica, social e economicamente vulnerabilizadas e o incremento destas devido à crise econômica e ao isolamento social; e à violência contra as mulheres.

Em três artigos, as(os) autoras(es) apresentam reflexões sobre as Diretrizes Curriculares Nacionais para os cursos de Graduação em Medicina (DCN) ${ }^{11}$ na ótica do ensino das políticas públicas ligadas às diversidades, como a Política de Equidade $^{12}$ e sua relação com a população LGBTIQIA+, temática rotineiramente invisibilizada, pois ainda persistem as desigualdades, as iniquidades e a presença de fobias de gênero nas instituições de ensino e na atenção à saúde. Para isso, esses manuscritos destacam a importância de estratégias de apoio para a população LGBTIQIA+ nas universidades e um olhar mais atento aos currículos médicos, para que eles estejam em consonância com as necessidades dessa população, de forma mais acolhedora, generosa e comprometida, com um ensino e cuidado que inspirem solidariedade e empatia, além do uso de mediações tecnológicas.

Na atual realidade, há a potencialização dessas situações com as experiências de sofrimento psíquico que ampliam antigas situações de vulnerabilidades e ainda acrescentam novos abalos no cotidiano de pessoas que não tinham problemas $^{13}$. A educadora e o educador em saúde necessitam estar atentas(os) à instituição de ensino e aos sentimentos das(os) discentes submetidas(os) a uma carga emocional aumentada que pode causar danos à saúde mental, para que assim possam contribuir com a proposição de estratégias de enfrentamento, prevenção e promoção da saúde mental às(aos) estudantes, o que podemos encontrar em dois artigos. A propósito, em um artigo também temos a reflexão da importância da equipe de cuidados paliativos destinados às(aos) pacientes e às famílias delas(es) impactados pela enfermidade oncológica e mais vulneráveis pela pandemia.

Quanto ao protagonismo discente, há também relatos que confirmam a importância da representação estudantil e de suas experiências como atrizes e atores principais nas decisões democráticas em relação às adaptações do ensino na pandemia. Essas ações nos convidam a pensar sobre o que decidimos, para quem decidimos e se realmente as decisões representam as reais necessidades, pensando sempre que "nada deles sem eles" deve estar no horizonte que observamos nas janelas do ensinar e aprender.

Também é possível encontrar neste suplemento cinco artigos sobre as experiências e soluções diante da emergente necessidade que a pandemia desvelou às(aos) educadoras(es) e educandas(os), a mudança do paradigma do ensino presencial em saúde, trazendo a necessidade de uma rápida adaptação ao uso de tecnologias pautadas na inclusão digital. Para que o ensino nessa perspectiva seja o mais efetivo e agradável às atrizes e aos atores envolvidas(os), pensar que a inclusão digital deve incluir todas(os), sem deixar ninguém de fora, fomentou em nível ampliado discussões e inovações pedagógicas mediadas pelas tecnologias.

Completando este número temático, destacamos que a população vivencia também uma grande disseminação das chamadas fake news, que aumentam a ansiedade e o temor das pessoas. Por conta disso, são necessárias medidas das(os) profissionais de saúde para minimizar os danos de informações equivocadas, erradas, inverídicas e, por vezes, criminosas. No caminho inverso das fake news, neste número temático temos um relato de experiência que envolve o protagonismo estudantil na produção de informação adequada para as pessoas idosas grupo vulnerável em relação à desinformação e com risco maior em relação à gravidade da doença.

E para terminar o editorial deste suplemento... gratidão a todos, todes e todas autoras(es) pelo conhecimento compartilhado com generosidade, pensamentos, histórias, gentileza, competência, experiências, reflexões, amorosidade e inquietações. Agradecemos ainda às(aos) avaliadoras(es) que conduziram cuidadosamente as avaliações de cada manuscrito, e, por fim, ao Conselho editorial da RBEM e à diretoria da Associação Brasileira de Educação Médica (Abem) a confiança depositada em nós como editora e editor convidada e convidado para este suplemento. E não podemos deixar de pautar nossos agradecimentos a todas(os) as(os) integrantes do grupo de trabalho Populações (In)Visibilizadas e Diversidades da Abem, bem como às(aos) demais parceiras(os) para a promoção de uma Educação Médica de 
qualidade e pautada na diversidade, nos Direitos Humanos e na justiça social. Agradecemos também a todas as pessoas que de alguma forma apoiam essa luta.

Neste momento em que o Sistema Único de Saúde brasileiro completa 30 anos, concretizando-se como a maior e melhor oportunidade de inclusão social como política pública por possibilitar o direito à saúde para todas(os), gostaríamos que o material aqui produzido e compartilhado auxilie na construção de novas realidades para as populações inviabilizadas e marginalizadas no Brasil, transformando a educação e a atuação daquelas(es) que cuidam/cuidarão de diferentes pessoas, em contextos de iniquidades e vulnerabilidades, para que assim possam promover o acesso equânime, universal e afetuoso durante e após a pandemia. $\mathrm{O}$ nosso mais profundo desejo é que esta edição temática abra as portas para outras que virão, com os mais diversos temas que inquietam o campo da Educação Médica.

\section{CONTRIBUIÇÃO DOS AUTORES}

A autora e o autor contribuíram igualmente na construção do artigo.

\section{CONFLITO DE INTERESSES}

A autora e o autor declaram não haver conflito de interesses.

\section{REFERÊNCIAS}

1. Carmo ME, Guizardi FL. O conceito de vulnerabilidade e seus sentidos para as políticas públicas de saúde e assistência social. Cad Saude Publica. 2017;34(3):e00101417. doi: 10.1590/0102-311X00101417.

2. Barata RB. Como e por que as desigualdades sociais fazem mal à saúde. Rio de Janeiro: Fiocruz; 2009.

3. Patel JA, Nielsen FBH, Badiani AA, Assi S, Unadkat VC, Patel B, et al. Poverty, inequality and COVID-19: the forgotten vulnerable. Public Health. 2020;183:110-1. doi: 10.1016/j.puhe.2020.05.006.

4. Raimondi GA, Souza LP de, Moraes VHA, Afonso DH, Borret RHES, Tourinho FSV, et al. Posicionamento do grupo de trabalho Populações (In) Visibilizadas e Diversidades a respeito das violências contra a população negra e do racismo estrutural. Rev Bras Educ Med. 2020;44(3):e093.

5. Minayo MCS, Freire NP. Pandemia exacerba desigualdades na Saúde. Cien Saude Colet. 2020;25(9) [acesso em 23 set 2020]. Disponível em: http://www.cienciaesaudecoletiva.com.br/artigos/pandemia-exacerbadesigualdades-na-saude/17579?id=17579.

6. Lancet T. Redefining vulnerability in the era of COVID-19. Lancet. 2020;395(10230):1089.

7. Signorelli $M$, Moretti-Pires RO, de Oliveira DC, Miskolci R, Polidoro $M$, Pereira PP. The health of LGBTI+ people and the COVID-19 pandemic: a call for visibility and health responses in Latin America. Sexualities. 2020 July 12;136346072094201. doi: 10.1177/1363460720942016.

8. Smith JA, Judd J. COVID-19: Vulnerability and the power of privilege in a pandemic. Health Promot J Austr. 2020 Apr;31(2):158-160.

9. Werneck GL, Carvalho MS. A pandemia de COVID-19 no Brasil: crônica de uma crise sanitária anunciada. Cad Saude Publica. 2020;36(5):e00068820.

10. Brasil. Constituição da República Federativa do Brasil. Brasília, DF: Senado Federal; 1988.

11. Brasil. Resolução $n^{\circ} 3$, de 20 de junho de 2014. Institui Diretrizes Curriculares Nacionais do Curso de Graduação em Medicina e dá outras providências. Brasília; 2014.

12. Brasil. Políticas de Promoção da Equidade em Saúde. Brasília: Ministério da Saúde; 2013.

13. Schmidt B, Crepaldi MA, Bolze SDA, Neiva-Silva L, Demenech LM. Saúde mental e intervenções psicológicas diante da pandemia do novo coronavírus (COVID-19). Estud Psicol (Campinas). 2020;37:e200063. 